\title{
Is asymptomatic peripheral arterial disease associated with walking endurance in patients with COPD?
}

This article was published in the following Dove Press journal:

International Journal of COPD

29 July 2015

Number of times this article has been viewed

\author{
Kuo-Shao Sun ${ }^{1,2, *}$ \\ Ming-Shian Lin ${ }^{1,2, *}$ \\ Yi-Jen Chen ${ }^{1,2}$ \\ Yih-Yuan Chen ${ }^{3}$ \\ Solomon Chih-Cheng Chen ${ }^{4}$ \\ Wei Chen ${ }^{1,5,6}$ \\ 'Division of Pulmonary and Critical \\ Care Medicine, ${ }^{2}$ Department of \\ Respiratory Care, Chang Gung \\ University of Science and Technology, \\ ${ }^{3}$ Department of Internal Medicine, \\ ${ }^{4}$ Department of Medical Research, \\ Ditmanson Medical Foundation \\ Chia-Yi Christian Hospital, Chiayi, \\ ${ }^{5}$ College of Nursing, Dayeh University, \\ Changhua, ${ }^{6}$ Department of Respiratory \\ Therapy, China Medical University, \\ Taichung, Taiwan, Republic of China \\ *These authors contributed equally \\ to this work
}

Objective: Symptomatic peripheral arterial disease (PAD) is associated with impaired walking endurance in patients with chronic obstructive pulmonary disease (COPD). However, it is unknown whether asymptomatic PAD is associated with impaired walking endurance in patients with COPD.

Methods: This prospective cross-sectional study enrolled 200 COPD patients (mean age: 70.9 years) who volunteered to perform ankle-brachial index (ABI) and 6-minute walk test (6MWT) consecutively. Demographic data, lung function, dyspnea scales, and cardiovascular risk factors were recorded. The ABI was used to detect PAD (ABI <0.90). All patients were free of PAD symptoms at enrollment.

Results: Of the 200 COPD patients, 17 (8.5\%) were diagnosed with asymptomatic PAD. The COPD patients without asymptomatic PAD did not walk significantly further on the 6MWT than the COPD patients with asymptomatic PAD ( $439 \pm 86 \mathrm{~m}$ vs $408 \pm 74 \mathrm{~m}, P=0.159)$. The strongest correlation with the distance walked on the 6MWT was Medical Research Council dyspnea scale $\left(r^{2}=-0.667, P<0.001\right)$, followed by oxygen-cost diagram $\left(r^{2}=0.582, P<0.001\right)$ and forced expiratory volume in 1 second $\left(r^{2}=0.532, P<0.001\right)$. In multivariate linear regression analysis, only age, forced expiratory volume in 1 second, and baseline pulse oximetry were independently correlated with the distance covered on the 6MWT $(P<0.05)$. However, body mass index, baseline heart rate, and ABI were not correlated with the distance covered on the 6MWT.

Conclusion: Asymptomatic PAD is not associated with walking endurance in patients with COPD. Therefore, it is important to detect and treat asymptomatic PAD early so that COPD patients do not progress to become exercise intolerant. Limited by the small sample size and predominantly male (99\%) population in the study, further large-scale prospective studies are needed to verify the results.

Keywords: peripheral arterial disease, COPD, ankle-brachial index, 6-minute walk tests

\section{Introduction}

Chronic obstructive pulmonary disease (COPD) is a global health issue with an estimated prevalence rate of around 5\%-13\%. ${ }^{1,2}$ Although irreversible airflow limitation resulting from an abnormal inflammatory response to inhaled particles and gases is the characteristic pathogenesis of COPD, it is not only a pulmonary disorder ${ }^{3}$ but also a systemic disease that contributes to exercise intolerance, depression, ${ }^{4,5}$ muscle dysfunction, ${ }^{6,7}$ and bone fractures from accelerated osteoporosis. ${ }^{8,9}$ Notably, COPD is an independent risk factor for cardiovascular mortality and morbidities, ${ }^{10,11}$ among which peripheral arterial disease (PAD) is highly prevalent in Western countries. ${ }^{12-14}$

PAD is a progressive, atherosclerotic process that affects noncoronary arteries and is defined by an ankle-brachial index (ABI) of $<0.9 .{ }^{15}$ PAD is typically
Correspondence: Wei Chen

Division of Pulmonary and Critical Care Medicine, Chia-Yi Christian Hospital,

539 Jhongsiao Road, Chiayi 600, Taiwan, Republic of China

Tel +886 5276504 I

Fax +886 527745 II

Email peteralfa2004@yahoo.com.tw 
asymptomatic before progressing to clinical stages ranging from intermittent claudication, foot ulcers, or pain on walking, to critical limb ischemia. ${ }^{16}$ Subsequently, the progression of PAD may result in functional decline and worse exercise performance over time. ${ }^{17}$ It is known that symptomatic PAD is associated with impaired walking endurance in patients with COPD. Castagna et al showed that the distance covered during the 6-minute walk test (6MWT) was positively associated with the degree of symptomatic PAD in COPD patients. ${ }^{12}$ However, it is unknown whether asymptomatic PAD is associated with walking endurance in patients with COPD.

In the current study, we performed a cross-sectional analysis of the Case Management Program and Integrated Care for patients with COPD (CMPICO) cohort $^{18}$ with 200 COPD patients enrolled during a 4-year period. The primary aim was to investigate the association between asymptomatic PAD and walking endurance, measured by the 6MWT in COPD patients. The second aim was to analyze which factors were associated with the distance achieved on the 6MWT by linear regression analysis.

\section{Materials and methods Study design}

In this cross-sectional study, we examined data (collected from January 2011 to November 2014) of participants enrolled in the CMPICO study. ${ }^{18}$ In brief, part of the CMPICO study was designed to investigate relevant comorbidities in patients with COPD such as osteoporosis, cardiovascular diseases, and psychological diseases. The study was carried out at the outpatient department of the Division of Pulmonary and Critical Care Medicine, Ditmanson Medical Foundation Chia-Yi Christian Hospital, which is a 1,000-bed community-based teaching hospital in Chiayi, Taiwan. The Institutional Review Board of Ditmanson Medical Foundation Chia-Yi Christian Hospital approved this study. The majority of the enrolled individuals provided written informed consent; however, there were a few illiterate subjects. Our team explained the study design thoroughly to these illiterate subjects, and if they agreed to participate, they signed consent forms using fingerprints instead of a written signature.

\section{Subjects}

COPD patients who volunteered to undergo ABI measurements and the 6MWT were enrolled in the CMPICO study. All of the patients were free of obvious symptoms of PAD such as intermittent claudication, foot ulcers, or pain on walking. The diagnosis of COPD was based on the Global
Initiative for Chronic Obstructive Lung Disease (GOLD) guidelines. ${ }^{19}$ The patients who were not current or former smokers with at least a 10-pack-year history were excluded. Eligible patients were 46-89 years of age with a postbronchodilator forced expiratory volume in 1 second $\left(\mathrm{FEV}_{1}\right)$ to forced vital capacity ratio of $<0.7 .{ }^{19}$ The patients with a history of bronchial asthma and other structural lung diseases (such as lung cancer, bronchiectasis, and fibrotic lung) were excluded. A chest physician carefully reviewed chest radiographs of all of the patients. A total of 200 patients (99\% male) with a mean age of $70.9 \pm 8.9$ years met the inclusion criteria and were enrolled. Once a participant was diagnosed as having asymptomatic PAD, they were referred to the Department of Cardiovascular Surgery for further management. Lifestyle changes (such as smoking cessation and exercise) and pharmacotherapy (for hypertension, diabetes, and hyperlipidemia) were then suggested.

\section{Data collection}

Interviews were conducted by a trained staff in charge of COPD case management who used a well-established questionnaire to collect demographic information of the study participants, including date of birth, sex, smoking status, and personal medical history. Body weight, height, and blood pressure were measured for each participant. Body mass index (BMI) was calculated as weight $(\mathrm{kg})$ divided by the square of the height $\left(\mathrm{m}^{2}\right)$. The subjects self-reported their medical history, including hypertension, hyperlipidemia, and diabetes mellitus, for which the diagnostic definitions were detailed in our previous study. ${ }^{18}$ Smoking status was also evaluated by a self-reported questionnaire.

\section{Measurement of $\mathrm{ABI}$}

Ankle and brachial pressures were measured using volume plethysmographic apparatus (VaSeraH VS-1000, Fukuda Denshi Co., Ltd., Tokyo, Japan). The procedure and method of measuring the ABI were also detailed in our previous report. ${ }^{18}$ Participants with an ABI score of $<0.9$ were defined as having PAD, and those with an ABI score of $\geq 0.9$ as not having PAD. ${ }^{15}$

\section{Six-minute walk test}

Performance on the 6MWT has been reported to be highly correlated with exercise capacity in patients with COPD, ${ }^{20,21}$ and physical activity is the strongest predictor of all-cause mortality in patients with COPD. ${ }^{22}$ The standard procedure of the 6MWT was based on the American Thoracic Society guidelines. ${ }^{23}$ A hallway in the hospital was used, and a 
distance of $30 \mathrm{~m}$ was outlined with markings on the floor at each end. Before the test, the patients completed several relevant simple questionnaires, including the oxygen-cost diagram, ${ }^{24,25}$ Medical Research Council (MRC) dyspnea scale, ${ }^{26}$ and Borg scale, ${ }^{27}$ and several physiological parameters (heart rate, blood pressure, and baseline pulse oximetry $\left.\left[\mathrm{SpO}_{2}\right]\right)$ were also measured for each patient.

The participants were asked to walk from one end to the other at their own pace, attempting to cover as much distance as possible. They were allowed to stop and rest as needed, but they were encouraged to continue walking after recovery. A trained research nurse timed the walk, recorded the total distance covered, and monitored $\mathrm{SpO}_{2}$ continuously throughout the test. Immediately after the test, all of the physiological parameters and Borg scale were measured again. Because $\mathrm{SpO}_{2}$ was recorded during the entire test, beginning, minimum, and end $\mathrm{SpO}_{2}$ values were recorded for each patient.

\section{Statistical analysis}

Data were analyzed using SPSS statistical software for Windows version 21 (IBM Corporation, Armonk, NY, USA). Continuous data were expressed as mean \pm standard deviation. The Student's $t$-test was used when data were normally distributed; otherwise, the nonparametric Mann-Whitney $U$-test was used. Categorical data were compared using the chi-square test if the observed numbers in all categories were larger than 5; otherwise, Fisher's exact test was used. Factors independently associated with distance achieved in the 6MWT were explored using a multiple linear regression model.

\section{Results}

During the 4-year study period, 200 patients with COPD were enrolled, $47 \%$ of whom were current smokers. The most predominant underlying disease was hypertension $(\mathrm{n}=98,49 \%)$, followed by diabetes mellitus $(\mathrm{n}=35,17.5 \%)$ and hyperlipidemia $(n=23,11.5 \%)$. According to the GOLD criteria, the percentages of mild, moderate, severe, and very severe COPD were $14 \%, 48 \%, 31 \%$, and $7 \%$, respectively. Of the 200 COPD patients, 17 (8.5\%) were diagnosed with asymptomatic $\mathrm{PAD}$.

Comparing the characteristics and pulmonary function tests between the COPD patients with and without asymptomatic PAD, those with asymptomatic PAD had a significantly higher rate of hyperlipidemia (35.3\% vs $9.3 \%$, $P=0.006$ ) and number of cigarette pack-years (69.2 vs 50.3 , $P=0.021)$ than the patients without asymptomatic PAD. There were no differences in age, BMI, smoking history, and pulmonary function tests between the two groups (Table 1).
Table I Demographic data of all enrolled COPD patients with and without asymptomatic PAD

\begin{tabular}{llll}
\hline & $\begin{array}{l}\text { PAD (+) } \\
(\mathbf{n}=17)\end{array}$ & $\begin{array}{l}\text { PAD (-) } \\
(\mathbf{n}=183)\end{array}$ & $\begin{array}{l}\text { P-value } \\
\text { Age }\end{array}$ \\
\hline Sex, male & $17.9 \pm 9$ & $70.9 \pm 9$ & 0.645 \\
BMI & $24.1 \pm 3.5$ & $22.8 \pm 3.5$ & 0.135 \\
Smoking & $17(100 \%)$ & $186(100 \%)$ & 1.000 \\
$\quad$ Current & $8(47.1 \%)$ & $86(47 \%)$ & 1.000 \\
$\quad$ Former & $9(52.9 \%)$ & $97(53 \%)$ & \\
Pack-years & $69.2 \pm 44$ & $50.3 \pm 30$ & 0.021 \\
DM & $6(35.3 \%)$ & $29(15.8 \%)$ & 0.086 \\
Hypertension & $11(64.7 \%)$ & $87(47.5 \%)$ & 0.210 \\
Hyperlipidemia & $6(35.3 \%)$ & $17(9.3 \%)$ & 0.006 \\
FEV & $1.20 \pm 0.4$ & $1.28 \pm 0.5$ & 0.571 \\
FEV $\%$ predicted & $55.9 \pm 19$ & $56.5 \pm 18$ & 0.907 \\
FEV,/FVC & $52.9 \pm 9$ & $54.8 \pm 8$ & 0.430 \\
MMEF\% & $20.2 \pm 8$ & $21.7 \pm 9$ & 0.380 \\
ABI & $0.86 \pm 0.1$ & $1.09 \pm 0.1$ & $<0.01$ \\
\hline
\end{tabular}

Abbreviations: COPD, chronic obstructive pulmonary disease; PAD, peripheral arterial disease; $\mathrm{BMI}$, body mass index; DM, diabetes mellitus; $\mathrm{FEV}_{\text {, }}$, forced expiratory volume in I second; FVC, forced vital capacity; MMEF, maximum mid-expiratory flow; $\mathrm{ABI}$, ankle-brachial index.

The COPD patients without asymptomatic PAD achieved a longer distance on the 6MWT than the COPD patients with asymptomatic $\mathrm{PAD}$, but the difference did not reach statistical significance ( $439 \pm 86$ vs $408 \pm 74 \mathrm{~m}, P=0.159$ ). In addition, there were no significant differences in any of the variables including dyspnea scales and physiological parameters obtained before and after the 6MWT between the two groups (Table 2).

Table 2 Variables obtained before and after the 6-minute walk test in COPD patients with and without asymptomatic PAD

\begin{tabular}{|c|c|c|c|}
\hline & $\begin{array}{l}\text { PAD (+) } \\
(n=\mid 7)\end{array}$ & $\begin{array}{l}\text { PAD (-) } \\
(n=183)\end{array}$ & $P$-value \\
\hline \multicolumn{4}{|c|}{ Baseline data obtained before the 6MWT } \\
\hline Oxygen-cost diagram & $4.8 \pm 1.5$ & $5.1 \pm 1.8$ & 0.504 \\
\hline MRC dyspnea scale & $2.7 \pm 0.8$ & $2.5 \pm 0.8$ & 0.246 \\
\hline Baseline Borg & $0.73 \pm 1.3$ & $0.65 \pm 1.1$ & 0.751 \\
\hline Baseline HR & $87 \pm 17$ & $83 \pm 15$ & 0.242 \\
\hline Systolic BP & $140 \pm 13$ & $138 \pm 17$ & 0.658 \\
\hline Diastolic BP & $82 \pm 8$ & $84 \pm 12$ & 0.447 \\
\hline Baseline $\mathrm{SpO}_{2}$ & $95 \pm 2$ & $95 \pm 2$ & 0.493 \\
\hline \multicolumn{4}{|c|}{ Data obtained at the end of the $6 \mathrm{MWT}$} \\
\hline HR & $113 \pm 24$ & $114 \pm 18$ & 0.868 \\
\hline Borg scale & $4.7 I \pm I .6$ & $4.58 \pm 1.6$ & 0.750 \\
\hline Minimum $\mathrm{SpO}_{2}$ & $90 \pm 3$ & $90 \pm 5$ & 0.974 \\
\hline End $\mathrm{SpO}_{2}$ & $92 \pm 3$ & $92 \pm 5$ & 0.919 \\
\hline 6MWT, m & $408 \pm 74$ & $439 \pm 86$ & 0.159 \\
\hline 6MWT (\% pred) & $93.2 \pm 17$ & $97.5 \pm 18$ & 0.354 \\
\hline
\end{tabular}

Abbreviations: COPD, chronic obstructive pulmonary disease; PAD, peripheral arterial disease; MRC, Medical Research Council; HR, heart rate; BP, blood pressure; $\mathrm{SpO}_{2}$, pulse oximetry oxygen saturation; 6MWT, 6-minute walk test; pred, predicted. 
Table 3 Pearson correlation $\left(r^{2}\right)$ between distance covered on the 6-minute walk test and physiological variables, dyspnea scales, and pulmonary function tests in all enrolled COPD patients $(\mathrm{n}=200)$

\begin{tabular}{lll}
\hline Variables & $\boldsymbol{r}^{\mathbf{2}}$ & $\boldsymbol{P}$-value \\
\hline $\mathrm{BMI}$ & 0.145 & $0.04 \mathrm{I}$ \\
$\mathrm{ABI}$ & 0.136 & 0.054 \\
Age & -0.476 & $<0.00 \mathrm{I}$ \\
Smoke, pack-year & -0.052 & 0.462 \\
MRC dyspnea scale & -0.667 & $<0.00 \mathrm{I}$ \\
Baseline Borg scale & -0.279 & $<0.00 \mathrm{I}$ \\
Oxygen-cost diagram & 0.582 & $<0.00 \mathrm{I}$ \\
Baseline SBP & -0.105 & 0.138 \\
Baseline DBP & -0.046 & 0.514 \\
Baseline SpO & 0.342 & $<0.00 \mathrm{I}$ \\
Minimum SpO & 0.400 & $<0.00 \mathrm{I}$ \\
Baseline HR & -0.183 & 0.009 \\
FEV & 0.532 & $<0.00 \mathrm{I}$ \\
MMEF & 0.515 & $<0.00 \mathrm{I}$ \\
\hline Abbrevati & &
\end{tabular}

Abbreviations: COPD, chronic obstructive pulmonary disease; BMI, body mass index; ABI, ankle-brachial index; MRC, Medical Research Council; SBP, systolic blood pressure; $\mathrm{DBP}$, diastolic blood pressure; $\mathrm{SpO}_{2}$, pulse oximetry oxygen saturation; $\mathrm{HR}$, heart rate; $\mathrm{FEV}_{1}$, forced expiratory volume in I second; MMEF, maximum midexpiratory flow.

Correlations between the distance covered on the 6MWT and several dyspnea scales and physiological variables were further analyzed by Pearson correlation tests. As expected, most of the variables were significantly correlated with the distance covered on the 6MWT $(P<0.05)$, except for cigarette packyear history, ABI value, and blood pressure. Of the enrolled patients, the strongest correlations with the 6MWT were the MRC dyspnea scale $\left(r^{2}=-0.667, P<0.001\right)$, followed by oxygen-cost diagram $\left(r^{2}=0.582, P<0.001\right)$ and $\mathrm{FEV}_{1}\left(r^{2}=0.532\right.$, $P<0.001$ ) (Table 3).

In multivariate linear regression analysis, only age, $\mathrm{FEV}_{1}$, and baseline $\mathrm{SpO}_{2}$ were significantly correlated with distance covered on the 6MWT $(P<0.05)$ in all enrolled COPD patients ( $\mathrm{n}=200)$, and BMI, baseline heart rate, and ABI were no longer correlated with the 6MWT (Table 4).

Table 4 Multiple linear regression analysis of factors associated with distance covered on the 6-minute walk test in all enrolled COPD patients $(n=200)$

\begin{tabular}{llll}
\hline Variable & $\begin{array}{l}\text { Standardized } \\
\text { coefficients - beta }\end{array}$ & $\begin{array}{l}\text { Student's } \\
\text { t-test }\end{array}$ & P-value \\
\hline Age & -0.348 & -5.998 & $<0.0001$ \\
$\mathrm{BMI}$ & 0.048 & 0.859 & 0.391 \\
$\mathrm{FEV}_{1}$ & 0.349 & 5.615 & $<0.001$ \\
${\text { Baseline } \mathrm{SpO}_{2}}_{2}$ & 0.132 & 2.209 & 0.028 \\
Baseline HR & -0.096 & -1.673 & 0.096 \\
$\mathrm{ABI}$ & 0.073 & 1.283 & 0.201 \\
\hline
\end{tabular}

Abbreviations: COPD, chronic obstructive pulmonary disease; BMI, body mass index; $\mathrm{FEV}_{1}$, forced expiratory volume in I second; $\mathrm{SpO}_{2}$, pulse oximetry oxygen saturation; $H R$, heart rate; $A B I$, ankle-brachial index.

\section{Discussion}

To the best of our knowledge, this is the first study to investigate the association between asymptomatic PAD and walking endurance in patients with COPD. We further evaluated whether asymptomatic PAD is an etiology of exercise intolerance in patients with COPD. Our results showed that the COPD patients without asymptomatic PAD did not cover a significantly longer distance on the 6MWT than the COPD patients with asymptomatic PAD. In multivariate linear regression analysis, only age, $\mathrm{FEV}_{1}$, and baseline $\mathrm{SpO}_{2}$ were significantly correlated with the distance covered on the 6MWT, but not ABI.

Previous studies have shown that symptomatic PAD is significantly correlated with poorer walking endurance, as represented by a shorter distance covered on the 6MWT. 12,21,28,29 Castagna et al reported that the effect of symptomatic PAD on exercise intolerance in patients with COPD is considerable. ${ }^{12}$ However, in the current study, asymptomatic PAD was not associated with impaired walking endurance in the patients with COPD. This suggests that it is not too late to recommend lifestyle changes (such as smoking cessation and exercise) and pharmacotherapy (for hypertension, diabetes, and hyperlipidemia) for patients in this stage. Therefore, early screening for PAD using ABI measurements as well as early management for COPD patients could possibly prevent patients from progressing to exercise intolerance.

McDermott et al reported that asymptomatic PAD is independently associated with impaired lower extremity function in women..$^{30}$ They used summary performance scores including $4 \mathrm{~m}$ walk, chair stand, and balance tests to represent lower extremity function. A possible explanation for their findings is that their participants were relatively healthy elderly women, which means a subtle change in physiological function could make a big difference. However, asymptomatic PAD may not have such a large impact on COPD patients, whose lung function and other comorbidities already dominate exercise performance.

Several questionnaires to evaluate the perception of dyspnea and quality of life have been developed for patients with COPD. Compatible with previous reports, ${ }^{31-33}$ the MRC dyspnea scale, Borg scale, and oxygen-cost diagram were all significantly correlated with the distance covered on the 6MWT in the patients with COPD in this study. Furthermore, we found that the MRC dyspnea scale had a stronger correlation with distance covered on the 6MWT than the other two scales, which is consistent with the GOLD committee's decision to use the MRC dyspnea scale for subgroup classification in their current guidelines. ${ }^{34}$ 
Interestingly, we found that resting, baseline $\mathrm{SpO}_{2}$ was independently correlated with distance covered on the 6MWT in the patients with COPD, which is compatible with a previous study in which more dyspnea after the 6MWT, lower baseline $\mathrm{SpO}_{2}$, worse oxygen saturation during the 6MWT, and a shorter distance covered were predictors of mortality in COPD patients. ${ }^{35}$ Since pulse oximetry is an inexpensive, noninvasive, and convenient tool to monitor oxygen saturation, patients with COPD should be advised to undergo regular check-up examinations for $\mathrm{SpO}_{2}$.

There are several limitations to this study. First, the number of patients with asymptomatic PAD was relatively small $(n=17,8.5 \%)$ and most of the enrolled patients were male (99\%). Thus, further large-scale prospective studies are needed to verify the results of this study. Second, most of the patients in this study were male (99\%), so the results may not apply to female patients.

In conclusion, asymptomatic PAD was not associated with walking endurance in patients with COPD. Therefore, it is important to detect and treat asymptomatic PAD early so that COPD patients do not progress to develop symptomatic $\mathrm{PAD}$ and become exercise intolerant.

\section{Disclosure}

The authors declared no potential conflicts of interest with respect to the research, authorship, and/or publication of this article.

\section{References}

1. Mannino DM, Buist AS. Global burden of COPD: risk factors, prevalence, and future trends. Lancet. 2007;370(9589):765-773.

2. Buist AS, Vollmer WM, Sullivan SD, et al. The burden of obstructive lung disease initiative (BOLD): rationale and design. COPD. 2005;2(2): 277-283.

3. O'Donnell DE, Laveneziana P. Dyspnea and activity limitation in COPD: mechanical factors. COPD. 2007;4(3):225-236.

4. Yohannes AM, Alexopoulos GS. Depression and anxiety in patients with COPD. Eur Respir Rev. 2014;23(133):345-349.

5. Mikkelsen RL, Middelboe T, Pisinger C, Stage KB. Anxiety and depression in patients with chronic obstructive pulmonary disease (COPD). A review. Nord J Psychiatry. 2004;58(1):65-70.

6. Wust RC, Degens H. Factors contributing to muscle wasting and dysfunction in COPD patients. Int J Chron Obstruct Pulmon Dis. 2007;2(3): 289-300.

7. Weise B. [Pneumology rehabilitation 1999. Summary of statements of the American Thoracic Society in Am J Respir Crit Care Med 159 (19991) 1666-1682]. Pneumologie. 2000;54(5):215-217.

8. Ferguson GT, Calverley PM, Anderson JA, et al. Prevalence and progression of osteoporosis in patients with COPD: results from the towards a revolution in COPD health study. Chest. 2009;136(6):1456-1465.

9. Romme EA, Smeenk FW, Rutten EP, Wouters EF. Osteoporosis in chronic obstructive pulmonary disease. Expert Rev Respir Med. 2013; 7(4):397-410.

10. Engström G, Hedblad B, Janzon L, Valind S. Respiratory decline in smokers and ex-smokers - an independent risk factor for cardiovascular disease and death. J Cardiovasc Risk. 2000;7(4):267-272.
11. Sin DD, Wu L, Man SF. The relationship between reduced lung function and cardiovascular mortality: a population-based study and a systematic review of the literature. Chest. 2005;127(6):1952-1959.

12. Castagna O, Boussuges A, Nussbaum E, Marqueste L, Brisswalter J. Peripheral arterial disease: an underestimated aetiology of exercise intolerance in chronic obstructive pulmonary disease patients. Eur $J$ Cardiovasc Prev Rehabil. 2008;15(3):270-277.

13. Blum A, Simsolo C, Sirchan R, Haiek S. "Obesity paradox" in chronic obstructive pulmonary disease. Isr Med Assoc J. 2011;13(11): 672-675.

14. Pecci R, De La Fuente Aguado J, Sanjurjo Rivo AB, Sanchez Conde P, Corbacho Abelaira M. Peripheral arterial disease in patients with chronic obstructive pulmonary disease. Int Angiol. 2012;31(5):444-453.

15. Weitz JI, Byrne J, Clagett GP, et al. Diagnosis and treatment of chronic arterial insufficiency of the lower extremities: a critical review. Circulation. 1996;94(11):3026-3049.

16. Leng GC, Lee AJ, Fowkes FG, et al. Incidence, natural history and cardiovascular events in symptomatic and asymptomatic peripheral arterial disease in the general population. Int J Epidemiol. 1996;25(6): 1172-1181.

17. McDermott MM, Liu K, Greenland P, et al. Functional decline in peripheral arterial disease: associations with the ankle brachial index and leg symptoms. JAMA. 2004;292(4):453-461.

18. Lin MS, Hsu KY, Chen YJ, Chen CR, Chen CM, Chen W. Prevalence and risk factors of asymptomatic peripheral arterial disease in patients with COPD in Taiwan. PLoS One. 2013;8(5):e64714.

19. Johannessen A, Nilsen RM, Storebø M, Gulsvik A, Eagan T, Bakke P. Comparison of 2011 and 2007 global initiative for chronic obstructive lung disease guidelines for predicting mortality and hospitalization. $\mathrm{Am}$ $J$ Respir Crit Care Med. 2013;188(1):51-59.

20. Lisboa BC, Barría PP, Yáñez VJ, Aguirre ZM, Díaz PO. [Six minutes walk for the assessment of patients with chronic obstructive pulmonary disease]. Rev Med Chil. 2008;136(8):1056-1064.

21. Nordanstig J, Broeren M, Hensäter M, Perlander A, Osterberg K, Jivegård L. Six-minute walk test closely correlates to "real-life" outdoor walking capacity and quality of life in patients with intermittent claudication. J Vasc Surg. 2014;60(2):404-409.

22. Waschki B, Kirsten A, Holz O, et al. Physical activity is the strongest predictor of all-cause mortality in patients with COPD: a prospective cohort study. Chest. 2011;140(2):331-342.

23. ATS Committee on Proficiency Standards for Clinical Pulmonary Function Laboratories. ATS statement: guidelines for the six-minute walk test. Am J Respir Crit Care Med. 2002;166(1):111-117.

24. McGavin CR, Artvinli M, Naoe H, McHardy GJ. Dyspnoea, disability, and distance walked: comparison of estimates of exercise performance in respiratory disease. $\mathrm{Br}$ Med J. 1978;2(6132):241-243.

25. Chuang $\mathrm{ML}$, Lee $\mathrm{CH}$, Lin IF. Using the oxygen-cost diagram in ramp-slope selection for dyspneic patients. Intern Med. 2010;49(14): 1325-1332.

26. Bestall JC, Paul EA, Garrod R, Garnham R, Jones PW, Wedzicha JA. Usefulness of the Medical Research Council (MRC) dyspnoea scale as a measure of disability in patients with chronic obstructive pulmonary disease. Thorax. 1999;54(7):581-586.

27. Mador MJ, Rodis A, Magalang UJ. Reproducibility of Borg scale measurements of dyspnea during exercise in patients with COPD. Chest. 1995; 107(6):1590-1597.

28. Blum A, Simsolo C, Sirchan R. Vascular responsiveness in patients with chronic obstructive pulmonary disease (COPD). Eur J Intern Med. 2014;25(4):370-373.

29. McDermott MM, Ferrucci L, Guralnik JM, et al. The ankle-brachial index is associated with the magnitude of impaired walking endurance among men and women with peripheral arterial disease. Vasc Med. 2010;15(4):251-257.

30. McDermott MM, Fried L, Simonsick E, Ling S, Guralnik JM. Asymptomatic peripheral arterial disease is independently associated with impaired lower extremity functioning the women's health and aging study. Circulation. 2000;101(9):1007-1012. 
31. Katsura H, Yamada K, Kida K. Usefulness of a linear analog scale questionnaire to measure health-related quality of life in elderly patients with chronic obstructive pulmonary disease. J Am Geriatr Soc. 2003;51(8): 1131-1135.

32. Ries AL. Minimally clinically important difference for the UCSD shortness of breath questionnaire, Borg Scale, and Visual Analog Scale. COPD. 2005;2(1):105-110.

33. Jones PW, Adamek L, Nadeau G, Banik N. Comparisons of health status scores with MRC grades in COPD: implications for the GOLD 2011 classification. Eur Respir J. 2013;42(3):647-654.
34. Koblizek V, Pecen L, Zatloukal J, et al. Real-life GOLD 2011 implementation: the management of COPD lacks correct classification and adequate treatment. PLoS One. 2014;9(11):e111078.

35. Golpe R, Pérez-de-Llano LA, Méndez-Marote L, Veres-Racamonde A. Prognostic value of walk distance, work, oxygen saturation, and dyspnea during 6-minute walk test in COPD patients. Respir Care. 2013;58(8): $1329-1334$.

\section{Publish your work in this journal}

The International Journal of COPD is an international, peer-reviewed journal of therapeutics and pharmacology focusing on concise rapid reporting of clinical studies and reviews in COPD. Special focus is given to the pathophysiological processes underlying the disease, intervention programs, patient focused education, and self management protocols.

\section{Dovepress}

This journal is indexed on PubMed Central, MedLine and CAS. The manuscript management system is completely online and includes a very quick and fair peer-review system, which is all easy to use. Visit http://www.dovepress.com/testimonials.php to read real quotes from published authors. 